\title{
Effects of Ti on Microstructure, Mechanical Properties and Corrosion Behavior of High-Strength Steel Weld Metals for Offshore Structures
}

\author{
Jianguo Chen ${ }^{1,2,3,{ }^{*}, \text { Yongmei Yang }}{ }^{1,4,5}$, Liqun Li $^{3}$, Zejun Wang $^{2}$, Huiying Xiao ${ }^{1,4,5, *}$, Yushun Wei ${ }^{2}$, \\ Tenghui Zhu ${ }^{1,4,5}$, Hong Sun ${ }^{1,4,5}$ \\ ${ }^{1}$ Tianjin Yongchang Welding Wire Co., Ltd., Tianjin 300300, PR China; \\ ${ }^{2}$ Tianjin Special Equipment Inspection Institute, Tianjin 300192, PR China; \\ ${ }^{3}$ School of Materials Science and Engineering, Harbin Institute of Technology, Harbin 150001, PR \\ China; \\ ${ }^{4}$ Tianjin key laboratory of high-end equipment manufacturing welding consumables and technology \\ enterprises, Tianjin 300300, PR China; \\ ${ }^{5}$ Tianjin Golden Bridge Welding Materials Group Co., Ltd., Tianjin 300300, PR China; \\ *E-mail: jianguo_chen123@163.com (Jianguo Chen), xiao731120@163.com(Huiying Xiao)
}

doi: $10.20964 / 2021.08 .36$

Received: 18 April 2021/ Accepted: 6 June 2021 / Published: 30 June 2021

\begin{abstract}
Micro-alloying elements significantly affect the microstructure, mechanical properties and corrosion behavior of the high-strength steel weld metals. In this paper, the effects of Ti content on the microstructure, mechanical properties and corrosion behavior of $690 \mathrm{MPa}$ level high-strength steel shielded metal arc welding (SMAW) weld metal were studied. It is indicated that the grain refinement strengthening is the main strengthening mechanism for the weld metals. The microstructure, the formation of the oxide, the mechanical properties, and the corrosion resistance of the weld metal were remarkably affected by the addition of Ti. With the increase of Ti content, the grains of the weld metal were refined. Both the tensile strength and corrosion resistance were improved, while the impact property decreased. The $\mathrm{Mn}$ and $\mathrm{Si}$ oxides were covered more completely by the Ti oxides with the increase of the Ti content, forming $\mathrm{Mn}, \mathrm{Si}$, and $\mathrm{Ti}$ complex oxides, which resulted in the increase of the acicular ferrite. However, excessive addition $(0.022 \mathrm{wt} . \%)$ of Ti led to the decrease of the acicular ferrite and the formation of lath bainite. The formation of lath bainiteis is the main reason for the deterioration of the impact property and corrosion resistance of the weld metal.
\end{abstract}

Keywords: Microstructure, Ti content, Weld metal, 690 MPa high-strength steel, Mechanical properties, Corrosion behavior 
(C) 2021 The Authors. Published by ESG (www.electrochemsci.org). This article is an open access article distributed under the terms and conditions of the Creative Commons Attribution license (http://creativecommons.org/licenses/by/4.0/). 